\title{
Qualidade dos pellets de biomassas brasileiras para aquecimento residencial: padrões da norma ISO 17225
}

\author{
Dorival Pinheiro Garcia ${ }^{1 *}$, José Cláudio Caraschi², Gustavo Ventorim², Glaucia Aparecida Prates², \\ Thiago De Paula Protásio 3 \\ ${ }^{1}$ Departamento de Tecnologia da Madeira, Faculdade de Ciências Sociais e Agrárias de Itapeva, Itapeva - SP, Brasil. \\ ${ }^{2}$ Curso de Engenharia Industrial Madeireira, Universidade Estadual Paulista, Itapeva - SP, Brasil. \\ ${ }^{3}$ Departamento de Ciências Florestais, Universidade Federal de Lavras, Lavras - MG, Brasil
}

\begin{abstract}
RESUMO Os pellets são biocombustíveis sólidos densificados negociados internacionalmente. O Brasil é apontado como um futuro exportador desse produto. Para isso, precisa atender rígidos padrões de qualidades exigidos pela norma ISO 17225. No entanto, poucos estudos abordam a qualidade dos pellets em relação aos parâmetros dessa normativa internacional de 2014. Este trabalho analisou as características físicas, químicas e térmicas de três tipos de pellets produzidos no Brasil, classificando e comparando-os com os requerimentos dessa normativa europeia. Os pellets de pinus, madeira nativa e bagaço de cana foram examinados por um laboratório europeu especializado nesses biocombustíveis sólidos. Os resultados mostraram que o teor de cinzas é a principal característica qualitativa negativa desses produtos. Em relação à norma, somente os pellets de pinus atenderam todos os critérios de qualidade e alcançaram padrão A1 Premium, podendo ser utilizado em aplicações nobres como o aquecimento residencial.
\end{abstract}

Palavras-chave: combustível sólido; bioenergia; peletização; densificação; biocombustível.

\section{Quality of Brazilian biomass pellets for residential heating: standards of ISO 17225}

\begin{abstract}
Pellets are densified biofuels, internationally traded. Brazil is considered the future exporter of this product. In order for all of this to occur, it has to meet the strict quality standards required by ISO 17225 . However, there are very few studies addressing the qualifications within the international standard guidelines of 2014. This work goes in depth analyzing the physical, chemical and thermal characteristics of three types of pellets produced in Brazil, classifying and comparing them according to the European standard requirements. Pellets made from pine, native wood and cane residues were examined by a European laboratory specialized in these solid biofuels. The results revealed that the ash was the only negative characteristic of these products. In relation to the standard, only the pellets made of pines fulfilled all the criteria, reaching the A1 Premium standard, with the ability of being used in noble operations such as the residential heating system.
\end{abstract}

Keywords: solid fuel; bioenergy; pelletizing; densification; biofuel.

\section{Introdução}

Durante os últimos cinco anos, os pellets se transformaram em um importante recurso energético mundial, especialmente para o continente europeu, onde seu mercado é estável e passa por rápido desenvolvimento (GARCIA et al., 2016).
Por ser um combustível renovável e menos poluente que os derivados do petróleo, os pellets são utilizados por países que precisam diminuir suas emissões poluentes para atender aos acordos firmados no Protocolo de Kyoto e ratificados na Conferência do Clima (COP21), que ocorreu na França, em dezembro de 2015 (ADAMS; LINDEGAARD, 2016). 
O consumo de pellets pelos europeus foi de 9,2 e 14,4 milhões de toneladas em 2009 e 2011, respectivamente (TOSCANO et al., 2014) e espera-se um consumo de 50,0 milhões de toneladas para 2020 (BISWAS et al., 2011). Para esses autores, os pellets se tornarão um dos principais produtos de biomassa sólida comercializados globalmente e o Brasil pode ser um importante exportador.

O Brasil produziu 49.390 e 75.000 toneladas em 2014 e 2015, respectivamente (GARCIA et al., 2016; 2017), mas tem capacidade produtiva instalada para produzir quatro vezes mais, além dos novos projetos que estão sendo anunciados para os próximos anos (GARCIA et al., 2016). Diante desse novo cenário que se apresenta para os pellets, é importante que as empresas atestem a qualidade de seus produtos para alcançar o mercado de exportação.

Não há norma brasileira que regulamente a qualidade dos pellets, mas muitos países europeus (Itália, Alemanha, Áustria e Suécia) desenvolveram seus próprios padrões de qualidade para a combustão, armazenamento e transporte desses biocombustíveis. Há três anos, com objetivo de unificar a certificação nestes mercados, lançou-se o conjunto de normas internacionais ISO 17225 (2014), partes de 1 a 8. Essa nova legislação fornece os padrões de qualidade limites para os produtos densificados (pellets, briquetes industrial e não industrial) produzidos por qualquer biomassa vegetal.

Os critérios estabelecidos nessa norma europeia exigem redução das emissões de gases do efeito estufa, elementos minerais e de metais pesados, visto que os pellets são utilizados principalmente em sistemas de aquecimento residencial e comercial (JAGUSTYN et al., 2016).

Os teores de cinzas dos pellets, na norma ISO 17225 (2014), são uns dos principais fatores analisados porque influenciam diretamente na combustão, causam baixa eficiência do queimador, incrustações, corrosões e, consequente- mente, aumentam as despesas com manutenção do equipamento (GARCÍA et al., 2015). Por isso, os pellets são classificados em comerciais (A1, A2, B), industriais (I1, I2, I3) e nãolenhosos (A, B) de acordo com o seu teor de cinzas (ISO $17225,2014)$.

Alguns artigos abordando a qualidade dos pellets brasileiros foram publicados recentemente (FARIA et al., 2016; PINTO et al., 2015; PROTÁSIO et al., 2015; SPANHOL et al., 2015), mas eles estão fundamentados nas normas individuais de cada país. Assim, ainda há uma lacuna do conhecimento em relação aos padrões normativos mais recente da ISO 17225 (2014). Logo, o objetivo deste trabalho foi classificar e comparar a qualidade dos pellets de pinus, pellets de madeira nativa e pellets de bagaço de cana-de-açúcar em relação a esses novos padrões internacionais.

\section{Material e Métodos}

Três tipos de pellets que já foram produzidos no Brasil são analisados: pellets de madeira de pinus, madeira nativa e bagaço de cana (Figura 1). Os pacotes com $15 \mathrm{~kg}$ de pellets de pinus foram fabricados com serragem de pinus (Pinus sp.), em uma indústria de pellets localizada no Estado de Santa Catarina. Os pellets de bagaço de cana-de-açúcar (Saccharum officinarum) foram fabricados em uma indústria de pellets no interior de São Paulo, com o bagaço gerado por uma indústria de açúcar e álcool da cidade de Itaí/SP. Já os pellets de madeira nativa foram produzidos em uma peletizadora $(300 \mathrm{~kg} / \mathrm{h}) \mathrm{na}$ cidade de Belém/PA, com serragem de ipê (Tabebuia spp), provenientes de uma serraria no município de Parauapebas/PA.

As amostras de pellets foram produzidas e coletadas entre os meses de maio a outubro de 2015, acondicionadas em embalagens plásticas e enviadas para um laboratório europeu, credenciado para realizar as análises de qualidade dos pellets de acordo com as especificações da norma ISO 17225 (2014). 


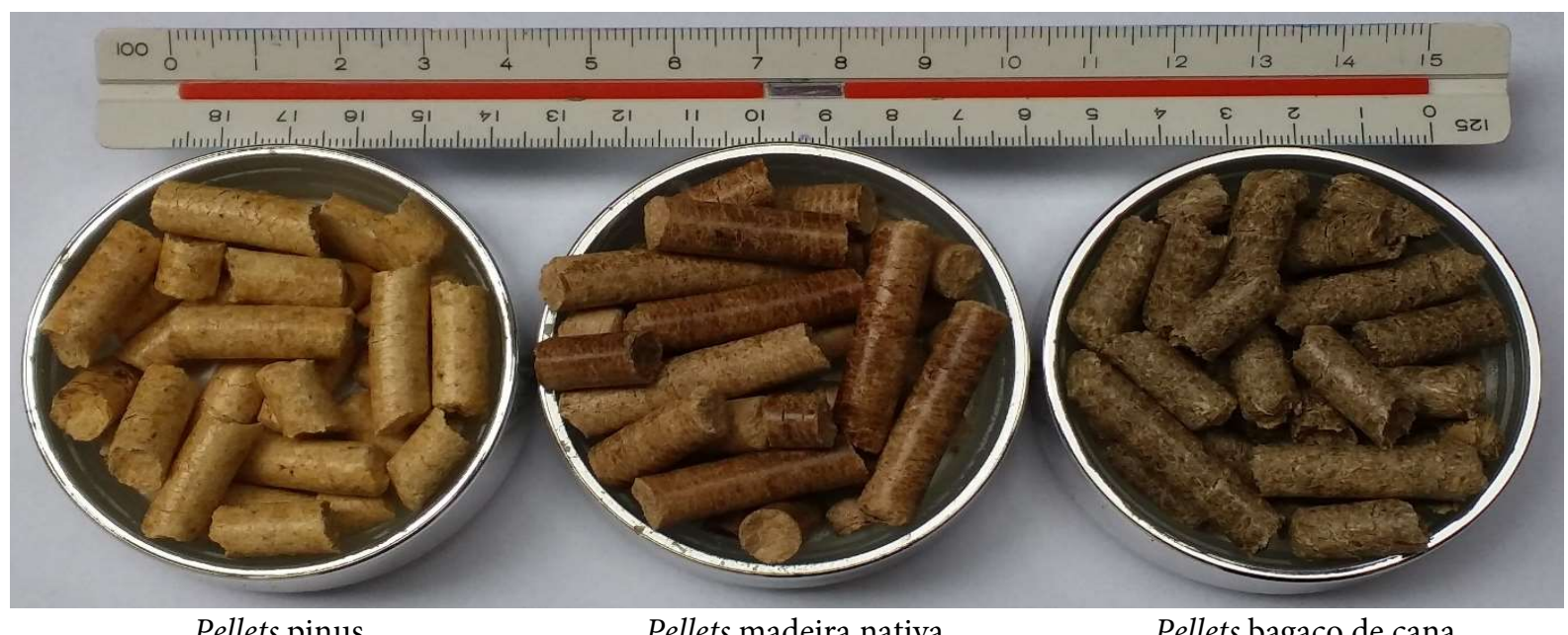

Pellets pinus

Pellets madeira nativa

Pellets bagaço de cana

Figura 1. Os três tipos de pellets utilizados nas análises

Figure 1. The three types of pellets used in the analysis

Tabela 1. Especificações de qualidade exigidos para os pellets, segundo a norma ISO 17225

Table 1. Quality specifications required for biofuel pellets, according to ISO 17225

\begin{tabular}{|c|c|c|c|c|c|}
\hline \multicolumn{2}{|c|}{$\begin{array}{l}\text { Norma Internacional } \\
\text { ISO } 17225-1\end{array}$} & \multirow{2}{*}{$\begin{array}{c}\text { Referência para os } \\
\text { ensaios } \\
\text { Aplicações } \\
\text { Classificação }\end{array}$} & \multicolumn{2}{|c|}{$\begin{array}{l}\text { Pellets de madeira } \\
\quad \text { ISO } 17225-2\end{array}$} & \multirow{2}{*}{$\begin{array}{c}\text { Pellets não-lenhoso } \\
\text { ISO 17225-6 } \\
\text { Geral } \\
\text { A }\end{array}$} \\
\hline Propriedades & Unid. & & $\begin{array}{l}\text { Residencial } \\
\text { A1 }\end{array}$ & $\begin{array}{l}\text { Comercial } \\
\text { A2 }\end{array}$ & \\
\hline Diâmetro & $\mathrm{mm}$ & ISO 17829 (2015) & \multicolumn{2}{|c|}{$6,0-8,0 \pm 1$} & $6,0-10,0$ \\
\hline Comprimento & $\mathrm{mm}$ & ISO 17829 (2015) & \multicolumn{2}{|c|}{$3,15-40,0$} & $3,15-40,0$ \\
\hline Densidade granel & $\mathrm{Kg} \mathrm{m}^{-3}$ & ISO 17828 (2015) & $\geq 600,0$ & $\geq 600,0$ & $\geq 600,0$ \\
\hline Teor de umidade & $\%$ & ISO 18134 (2015) & $\leq 10,0$ & $\leq 10,0$ & $\leq 12,0$ \\
\hline Teor de cinzas & $\%$ & ISO 18122 (2015) & $\leq 0,70$ & $\leq 1,20$ & $\leq 6,00$ \\
\hline Poder cal. (PCI) & $\mathrm{MJ} \mathrm{kg}^{-1}$ & ISO 18125 (2015) & $\geq 16,5$ & $\geq 16,5$ & $\geq 14,1$ \\
\hline Densidade energ. & $\mathrm{GJ} \mathrm{m}^{-3}$ & PCI x $\mathrm{D}_{\mathrm{g}}$ & no & no & no \\
\hline Enxofre & $\%$ & ISO 16994 (2016) & $\leq 0,04$ & $\leq 0,05$ & $\leq 0,20$ \\
\hline Carbono & $\%$ & ISO 16948 (2015) & no & no & no \\
\hline Hidrogênio & $\%$ & ISO 16948 (2015) & no & no & no \\
\hline Oxigênio & $\%$ & Por diferença & no & no & no \\
\hline Nitrogênio & $\%$ & ISO 16948 (2015) & $\leq 0,30$ & $\leq 0,50$ & $\leq 1,50$ \\
\hline Cloro & $\%$ & ISO 16994 (2016) & $\leq 0,02$ & $\leq 0,02$ & $\leq 0,20$ \\
\hline Cádmio & $\mathrm{mg} \mathrm{kg}^{-1}$ & ISO 16968 (2015) & $\leq 0,50$ & $\leq 0,50$ & $\leq 0,50$ \\
\hline Crômio & $\mathrm{mg} \mathrm{kg}^{-1}$ & ISO 16968 (2015) & $\leq 10,0$ & $\leq 15,0$ & $\leq 50,0$ \\
\hline Cobre & $\mathrm{mg} \mathrm{kg}^{-1}$ & ISO 16968 (2015) & $\leq 10,0$ & $\leq 20,0$ & $\leq 20,0$ \\
\hline Mercúrio & $\mathrm{mg} \mathrm{kg}^{-1}$ & ISO 16968 (2015) & $\leq 0,10$ & $\leq 0,10$ & $\leq 0,10$ \\
\hline Chumbo & $\mathrm{mg} \mathrm{kg}^{-1}$ & ISO 16968 (2015) & $\leq 10,0$ & $\leq 20,0$ & $\leq 10,0$ \\
\hline Zinco & $\mathrm{mg} \mathrm{kg}^{-1}$ & ISO 16968 (2015) & $\leq 100,0$ & $\leq 200,0$ & $\leq 100,0$ \\
\hline Durabilidade mecânica & $\%$ & ISO 17831 (2015) & $\geq 98,0$ & $\geq 97,5$ & $\geq 97,5$ \\
\hline Fusibilidade & ${ }^{\circ} \mathrm{C}$ & EN 15370-1 (2006) & $\geq 1200$ & $\geq 1100$ & $\geq 1100$ \\
\hline
\end{tabular}

no= parâmetros não obrigatórios; $\mathrm{PCI}=$ poder calorífico inferior; $\mathrm{D}_{\mathrm{g}}=$ densidade a granel 
Essas especificações e parâmetros físicos, químicos e térmicos dos pellets são apresentados na Tabela 1, bem como a norma de referência para a execução de cada ensaio, como determinado nas partes 2 e 6 (ISO 17225, 2014), para a madeira e material não-lenhoso, respectivamente.

Embora não sejam obrigatórios para certificação da qualidade, densidade energética, teores de carbono, hidrogênio e oxigênio são importantes na utilização dos pellets e por isso foram determinados.

Uma limitação desse estudo está no fato do laboratório credenciado apresentar um relatório com os resultados médios, o que impossibilita a realização de estudos estatísticos de variabilidade dos dados. Entretanto, a confiabilidade dos resultados é garantida por ser laboratório comercial credenciado e especializado nas análises neste padrão normativo, possuir todos os equipamentos necessários e repetir o processo constantemente, conforme as orientações de certificação descritas na norma ISO 17225 (2014).

\section{Resultados e Discussão}

Os resultados das análises efetuadas, de acordo com essa norma europeia, são apresentados na Tabela 2.

Os diâmetros das amostras de pellets variaram entre 6,0$6,1 \mathrm{~mm}$, semelhantes aos valores encontrados por Alakangas (2005) e Duca et al. (2014). Esses autores destacaram que os diâmetros finais tiveram pequenas variações porque foram produzidos com uma matriz perfurada com diâmetro padronizado de 6,0 $\mathrm{mm}$ e as oscilações representam apenas pequenos desgastes no canal ou adsorção de umidade do ambiente. Os valores atendem as exigências da norma ISO 17225 (2014) e o diâmetro uniforme é um fator importante na combustão porque proporcionam estabilidade na queima do biocombustível, sobretudo em pequenos queimadores residenciais (NADIAH; ABD 2016).
Quanto ao comprimento, os três pellets apresentaram valores superiores às referências listadas na Tabela 2. No entanto, esses tamanhos atendem aos requisitos normativos porque se encontram abaixo do limite máximo especificado que é de 40,0 mm. Em aplicações de pequeno porte, como aquecimento residencial, fornos de pizzarias, padarias e lavanderias, movidos à pellets, recomenda-se comprimentos menores que 20,0 mm, devido ao diâmetro da rosca sem fim, que pode ser obstruída causando a parada do equipamento e até a queima dos motores elétricos do sistema (TUMULURU, 2014).

Os valores para a densidade a granel, variaram entre 583,6 e 710,0 $\mathrm{kg} \mathrm{m}^{-3} \mathrm{e}$ estão coerentes com a literatura de referência (Tabela 2) e a norma ISO 17225 (2014). Alta densidade energética proporciona ganhos logísticos no transporte de energia porque é possível transportar maior massa de pellets em um menor volume de carga (FARIA et al., 2016; GARCIA et al., 2013; NADIAH; ABD, 2016; PEREIRA et al., 2016). Assim, os valores da densidade energética dos três tipos de pellets desse estudo são semelhantes a Alakangas (2005) e Duca et al. (2014), porém os pellets de pinus têm 36,96\% e 35,59\% mais energia por volume do que os pellets de madeira nativa $\mathrm{e}$ bagaço de cana, respectivamente. Portanto, há uma correlação direta entre densidade a granel e densidade energética, que na prática se traduzem em possibilitar o carregamento de mais energia no mesmo espaço do caminhão ou navio cargueiro, barateando o custo final do serviço de transporte e tornando esse biocombustível mais competitivo.

Os requisitos da norma ISO 17225 (2014) recomendam, para os pellets de madeira, umidades abaixo de $10 \%$. Desta forma, os pellets de madeira nativa, não alcançaram os padrões normativos, apresentando valor superior à literatura apresentada na Tabela 2. A umidade do biocombustível influencia diretamente na quantidade de energia disponível após a combustão. Assim, quanto maior a umidade, maior a parte da 
energia que será utilizada para a sua vaporização (SPANHOL et al., 2015). No entanto, ressalta-se que essa pequena variação da umidade ( $0,65 \%$ acima da norma) pode ser facilmente contornada com ajustes no processo de secagem da matériaprima. Além disso, baixos teores de umidade nos pellets são necessários para se obter maior eficiência na combustão, além de prolongar o tempo de estocagem do produto, minimizando a proliferação de fungos e a deterioração do material (GARCIA et al., 2013).

O teor de cinzas é fundamental para a qualidade energética dos pellets porque elevados teores aumentam os custos de manutenção dos equipamentos queimadores e contribuem para a redução do poder calorífico, uma vez que os elementos minerais, que compõem as cinzas, não participam do processo de combustão (PROTÁSIO et al., 2012).

Os pellets de pinus e de madeira nativa apresentaram teores de cinzas maiores do que Alakangas (2005) e menores do que Duca et al. (2014). A pequena diferença no teor de minerais desses dois pellets (0,17\%), que podem estar associados à fatores como tipos de solo, espécie vegetal, local de plantio, absorção de nutrientes entre outras variáveis (Vassilev et al., 2010), é o suficiente para separá-los em diferentes classificações, de acordo com a norma ISO 17225

Tabela 2. Resultados das análises dos três pellets comerciais incluindo dados de duas referências da literatura

Table 2. Results of the analyzes of the three commercial pellets including data two references of the literature

\begin{tabular}{|c|c|c|c|c|c|c|}
\hline \multirow[b]{2}{*}{ Propriedades } & \multirow[b]{2}{*}{ Unid. } & \multirow{2}{*}{$\begin{array}{c}\text { Pellets de } \\
\text { madeira Pinus }\end{array}$} & \multirow{2}{*}{$\begin{array}{c}\text { Pellets de } \\
\text { madeira } \\
\text { nativa }\end{array}$} & \multirow{2}{*}{$\begin{array}{c}\text { Pellets de } \\
\text { bagaço } \\
\text { de cana }\end{array}$} & \multicolumn{2}{|c|}{ Referências } \\
\hline & & & & & $\begin{array}{c}\text { Alakangas } \\
(2005)\end{array}$ & $\begin{array}{c}\text { Duca et al. } \\
(2014)\end{array}$ \\
\hline Diâmetro & $\mathrm{mm}$ & 6,10 & 6,10 & 6,00 & $6,0-8,0$ & 6,10 \\
\hline Comprimento & $\mathrm{mm}$ & 20,30 & 21,70 & 18,42 & $7,0-19,0$ & 17,10 \\
\hline Densidade granel & $\mathrm{Kg} \mathrm{m}^{-3}$ & 710,0 & 583,6 & 608,8 & $560,0-690,0$ & 696,5 \\
\hline Umidade $_{\text {base seca }}$ & $\%$ & 6,10 & 10,65 & 7,27 & $5,20-9,70$ & 6,70 \\
\hline Teor de cinzas & $\%$ & 0,60 & 0,77 & 1,95 & $0,24-0,37$ & 0,90 \\
\hline Poder cal. (PCI) & $\mathrm{MJ} \mathrm{kg-1}$ & 19,15 & 17,02 & 16,48 & $16,7-17,9$ & 17,0 \\
\hline Densidade energ. & $\mathrm{GJ} \mathrm{m}^{-3}$ & 13,60 & 9,93 & 10,03 & $9,30-12,30$ & 11,84 \\
\hline Enxofre & $\%$ & 0,040 & 0,020 & 0,100 & $0,004-0,007$ & $0,090^{1}$ \\
\hline Carbono & $\%$ & 51,82 & 52,44 & 50,64 & $49,12-49,80$ & $52,80^{1}$ \\
\hline Hidrogênio & $\%$ & 6,14 & 6,25 & 6,08 & $6,03-6,13$ & $6,10^{1}$ \\
\hline Oxigênio & $\%$ & 41,80 & 41,10 & 42,98 & $43,92-44,76$ & $40,81^{1}$ \\
\hline Nitrogênio & $\%$ & 0,20 & 0,19 & 0,20 & $0,05-0,16$ & $0,20^{1}$ \\
\hline Cloro & $\%$ & 0,01 & 0,03 & 0,03 & $0,06-0,07$ & 0,01 \\
\hline Cádmio & $\mathrm{mg} \mathrm{kg}^{-1}$ & 0,03 & 0,01 & 0,07 & $0,06-0,11$ & 0,20 \\
\hline Crômio & $\mathrm{mg} \mathrm{kg}^{-1}$ & 1,00 & 5,00 & 2,70 & $0,31-1,59$ & 0,80 \\
\hline Cobre & $\mathrm{mg} \mathrm{kg}^{-1}$ & 1,60 & 5,00 & 3,50 & $1,02-2,76$ & 2,60 \\
\hline Mercúrio & $\mathrm{mg} \mathrm{kg}^{-1}$ & 0,08 & 0,02 & 0,03 & $0,01-0,03$ & 0,10 \\
\hline Chumbo & $\mathrm{mg} \mathrm{kg}^{-1}$ & 2,10 & 4,00 & 0,70 & $0,6-14$ & 1,60 \\
\hline Zinco & $\mathrm{mg} \mathrm{kg}^{-1}$ & 5,60 & 7,90 & 9,60 & $7,04-8,0$ & 10,90 \\
\hline Durabilidade mec. & $\%$ & 98,6 & 97,7 & 97,5 & $97,4-98,9$ & 98,0 \\
\hline Fusibilidade & ${ }^{\circ} \mathrm{C}$ & 1306 & 1290 & 1255 & $1230-1290$ & $1300^{2}$ \\
\hline
\end{tabular}

Alakangas (2005), diversas espécies de madeiras; Duca et al. (2014), madeira de coníferas; ${ }^{1}$ Vassilev et al. (2010), cavacos de pinus; ${ }^{2}$ Vassilev et al. (2014), cavacos de beech wood (Faia). 
(2014): pellets de pinus, classificado como A1 Premium é recomendado para uso residencial; pellets de madeira nativa, classificado como A2 é indicado para uso geral, uma vez que pode ter até $1,2 \%$ de cinzas (Tabela 1 ).

Para os pellets não-lenhosos como o bagaço de cana, a norma ISO 17225-6 (2014), estabelece limites de até 6,0\% de cinzas e poder calorífico inferior $\geq 14,1 \mathrm{MJ} \mathrm{kg}^{-1}$, para os biocombustíveis classe A. Timung et al. (2015), analisaram o bagaço de cana e obtiveram 1,7\% de cinzas e 17,2 $\mathrm{MJ} \mathrm{kg}^{-1}$, para o poder calorífico inferior. Esses valores estão próximos dos obtidos nesse estudo. Assim, esses pellets atenderam a exigência da referida normativa europeia e podem ser classificados como adequados para uso geral não-residencial.

Os teores de enxofre desse estudo foram superiores aos relatados por Alakangas (2005) e menores do que Vassilev et al. (2010), com exceção para os pellets de bagaço de cana que apresentaram resultados superiores a todos os autores citados na Tabela 2. No entanto, as três amostras de pellets estão em conformidade com a norma ISO 17225 (2014).

Quantificando-se os teores de nitrogênio e enxofre podese estimar o impacto ambiental associado à queima do material lignocelulósico, pois durante a combustão esses elementos são convertidos em óxidos $\mathrm{NO}_{\mathrm{x}}$ e $\mathrm{SO}_{\mathrm{x}}$, respectivamente, que podem resultar em chuva ácida, corrosão dos fornos e caldeiras, acidificação de solos e danos à camada de ozônio (DEMIRBAS, 2004; CARROLL E FINNAN, 2012). A literatura especializada tem relatado baixas concentrações de nitrogênio e enxofre para a madeira e resíduos lignocelulósicos (PROTÁSIO et al., 2013b). Logo, as emissões de gases $\mathrm{NO}_{\mathrm{x}}$ e $\mathrm{SO}_{\mathrm{x}}$, a partir da queima desses materiais, podem ser consideradas negligenciáveis. Assim, para o teor de nitrogênio, os pellets de pinus, madeira nativa e bagaço de cana apresentaram valores maiores que os obtidos por Alakangas (2005) e semelhantes aos de Vassilev et al. (2010). Mas, ainda assim, estão em conformidade com os padrões estabelecidos na norma para esses materiais.

Os teores de cloro das amostras de pellets (Tabela 2) são menores do que os valores encontrados por Alakangas (2005) e semelhantes aos declarados por Duca et al. (2014). Assim, de acordo com a normativa europeia ISO 17225 (2014), os pellets de madeira nativa não estariam em conformidade por conterem teores de cloro $50 \%$ acima do permitido.

Alguns autores (AHMAD et al., 2016; MIRANDA et al., 2009) considerarem que os teores de enxofre, nitrogênio e cloro são tão pequenos que podem ser desprezados, na simplificação dos cálculos. Porém, outros pesquisadores (DUCA et al., 2014; JAGUSTYN et al., 2016; KIRSTEN et al., 2016) associam o cloro à problemas de corrosão nos equipamentos queimadores, e os teores de nitrogênio e enxofre ao aumento das emissões gasosas na queima dos pellets.

Os teores de carbono e hidrogênio (Tabela 2) são maiores do que Alakangas (2005), enquanto os teores de oxigênio, ao contrário, foram menores. Os resultados também são discordantes de Protásio et al. (2013a). As divergências dos resultados desse estudo com esses autores estão associados à diversos fatores como tipos de solo, espécie vegetal, local de plantio, entre outras variáveis, como foi detectado por Vassilev et al. (2010) nos seus estudos de revisão sobre a composição da biomassa vegetal.

Carbono, hidrogênio e oxigênio não têm limites estabelecidos na normativa europeia de qualidade, mas com essa composição química elementar do combustível é possível realizar cálculos ou simulações de combustão e desenvolver projetos de sistemas de conversão da biomassa vegetal em energia térmica (PROTÁSIO et al., 2013a). Por isso, é comum as análises laboratoriais trazerem os resultados em porcentagens de carbono, hidrogênio e nitrogênio. Além disso, Protásio et al. (2011) destacaram a existência de 
correlações positivas (carbono e hidrogênio) e negativas (cinzas, oxigênio) com o poder calorífico dos pellets.

Traços de metais pesados como o cádmio, crômio, cobre, mercúrio, chumbo e zinco foram detectados nas amostras de pellets e, no geral, esses resultados são semelhantes à literatura de referência da Tabela 2. Embora existam algumas discrepâncias nesses valores, todos os tipos de pellets apresentaram resultados em conformidade com a norma ISO 17225 (2014). Baixos teores de metais pesados são importantes para a qualidade dos pellets porque são associados as emissões de particulados, influenciam o ponto de fusão das cinzas, reciclagem e a disposição das cinzas residuais (ACDA; DEVERA, 2014).

A durabilidade mecânica das três amostras de pellets estão entre 97,5-98,6\% e são semelhantes às referências citadas na Tabela 2. A norma exige resultados maiores que $97,5 \%$ como parâmetro mínimo de qualidade para se obter a certificação para a exportação. Desta forma, os três pellets apresentaramse em conformidade com os padrões da norma ISO 17225 (2014). Para Tumuluru (2014), a durabilidade mecânica dos pellets é um indicador de resistência à compressão e impactos durante a movimentação. Dessa maneira, pode-se inferir que os três produtos apresentaram alta resistência mecânica, sobretudo os pellets de pinus. Na prática, ao transportar e armazenar esses biocombustíveis sólidos, existe baixa possibilidade de gerar poeira e partículas finas, minimizando possíveis riscos de explosões nos compartimentos de carga.

O comportamento das cinzas à fusão (fusibilidade) indica a facilidade com que os materiais inorgânicos da biomassa vegetal se fundem. A baixa temperatura de fusão das cinzas residuais $\left(<1.100^{\circ} \mathrm{C}\right)$ é apontada por alguns autores (VASSILEV et al., 2013; 2014) como principal fator gerador de escórias e incrustações durante a combustão. Por isso, a norma ISO 17225 (2014), estabelece valores superiores a $1.100^{\circ} \mathrm{C}$ como limite mínimo para a qualidade dos pellets.
Assim, altas temperaturas de fusão são benéficas para se obter combustíveis sólidos de melhor qualidade. Portanto, os pellets de madeira desse estudo, com fusibilidade entre 1.290$1.306^{\circ} \mathrm{C}$, têm melhores características na queima do que os pellets de bagaço de cana $\left(1.255^{\circ} \mathrm{C}\right)$. Dessa forma, a temperatura de fusão das cinzas dos pellets de pinus, de madeira nativa e bagaço de cana, apresentados na Tabela 2, estão em conformidade com a norma europeia (Tabela 1), habilitando-os a classificação A1 (para uso residencial), A2 (para uso comercial) e A (para uso industrial), respectivamente.

\section{Conclusões}

De acordo com os padrões para os pellets estabelecidos na norma ISO 17225, este estudo conclui que:

- Os pellets de pinus cumpriram todos os padrões de qualidade exigidos e têm classificação A1 Premium, certificados e indicados para uso residencial.

- Os pellets de madeira nativa não atendem aos padrões mínimos de qualidade para exportação, podem ser classificados como A2, sobretudo por conterem elevados teores de cinzas;

- Os pellets de bagaço de cana-de-açúcar, classificados na norma como não-lenhosos, são recomendados para uso industrial e têm classificação A.

\section{Referências}

ADAMS, P. W. R.; LINDEGAARD, K. A critical appraisal of the effectiveness of UK perennial energy crops policy since 1990. Renewable and Sustainable Energy Reviews, v. 55, p. 188-202, 2016.

BISWAS, A. K.; YANG, W.; BLASIAK, W. Steam pretreatment of Salix to upgrade biomass fuel for wood pellet production. Fuel Processing Technology, v. 92, n. 9, p. 17111717, 2011.

ACDA, M. N.; DEVERA, E. E. Physico-chemical properties of wood pellets from forest residues. Journal of Tropical Forest Science, v. 26, n. 4, p. 589-595, 2014. 
AHMAD, A. A.; ZAWAWI, N. A.; KASIM, F. H.; INAYAT, A.; KHASRI, A. Assessing the gasification performance of biomass: A review on biomass gasification process conditions, optimization and economic evaluation. Renewable and Sustainable Energy Reviews, v. 53, p. 1333 1347, 2016.

ALAKANGAS, E. Properties of wood fuels used in Finland. Biosouth Project, Technical Research Centre of Finland, VTT Processes: 2005. 104 p.

CARROLL, J. P.; FINNAN, J. Physical and chemical properties of pellets from energy crops and cereal straws. Biosystems Engineering, v. 112, n. 2, p. 151-159, 2012.

DEMIRBAS, A. Determination of calorific values of bio-chars and pyro-oils from pyrolysis of beech trunkbarks. Journal of Analytical and Applied Pyrolysis, v.72, p.215-219, 2004.

DUCA, D.; RIVA, G.; PEDRETTI, E.F.; TOSCANO, G. Wood pellet quality with respect to EN 14961-2 standard and certifications. Fuel, v. 135, p. 9-14, 2014.

EUROPEAN COMMITTEE FOR STANDARDIZATION (CEN) - EN 15370-1:2006 - Solid biofuels. Method for the determination of ash melting behaviour. Characteristic temperatures method, Brussels, 2006.

FARIA, W. S.; PROTÁSIO, T.P.; TRUGILHO, P.F.; PEREIRA, B.L.C.; CARNEIRO, A.C.O.; ANDRADE, C.R.; GUIMARÃES JÚNIOR, J.B. Transformação dos resíduos lignocelulósicos da cafeicultura em pellets para geração de energia térmica. Coffee Science, v. 11, n. 1, p. 137-147, 2016.

GARCIA, D. P.; CARASCHI, J. C.; VENTORIM, G.; VIEIRA, F.H.A. Trends and challenges of origin brazilian agroforestry pellets industry. Cerne, v. 22, n. 3, p. 233-240, 2016.

GARCIA, D. P.; CARASCHI, J. C.; VENTORIM, G. Caracterização energética de pellets de madeira. Revista da Madeira, v. 135, n. 2, p. 14-18, 2013.

GARCIA, D. P.; CARASCHI, J. C.; VENTORIM, G. O setor de pellets de madeira no Brasil. Revista Ciência da Madeira, v. 8, n. 1, p. $21-28,2017$.

GARCÍA, R.; PIZARRO, C.; ÁLVAREZ, A.; LAVÍN, A G.; BUENO, J. L. Study of biomass combustion wastes. Fuel, v. 148, p. 152-159, 2015.

INTERNATIONAL ORGANIZATION

FOR
STANDARDIZATION. ISO 16948: 2015 - Determination of total content of carbon, hydrogen and nitrogen. Brussels, 2014.

ISO 16968: 2016 - Solid biofuels - Determination of minor elements. Brussels, 2014.

.ISO 16994: 2016 - Solid biofuels - Determination of total content of sulfur and chlorine. Brussels, 2014.

.ISO 17225-1: 2014 - Solid biofuels - Fuel specifications and classes - Part 1: General requirements. Brussels, 2014.

.ISO 17225-2: 2014 - Solid biofuels - Fuels especication and classes - Part 2 - Graded pellets. Brussels, 2014.

.ISO 17225-6: 2014 - Solid biofuels - Fuels especication and classes - Part 6 - Graded non-woody pellets. Brussels, 2014.

.ISO 17828: 2015 - Solid biofuels - Determination of bulk density. Brussels, 2015.

.ISO 17829: 2015 - Solid biofuels - Determination of length and diameter of pellets. Brussels, 2015.

.ISO 17831: 2015 - Solid biofuels - Determination of mechanical durability of pellets - part 1. Brussels, 2015 .

ISO 18122: 2015 - Solid biofuels - Determination of ash content. Brussels, 2015.

ISO 18125: 2015 - Solid biofuels - Determination of calorific value. Brussels, 2015.

ISO 18134: 2015 - Solid biofuels - Determination of moisture content - part 1. Brussels, 2015.

JAGUSTYN, B.; KMIEC, M.; SMEDOWSKI, L.; SAJDAK, M. The content and emission factors of heavy metals in biomass used for energy purposes in the context of the requirements of international standards. Journal of the Energy Institute, v. 91, n. 1, p. 1-11, 2016.

KIRSTEN, C.; LENZ, V.; SCHRÖDER, H. W.; REPKE, J. U. Hay pellets - The influence of particle size reduction on their physical-mechanical quality and energy demand during production. Fuel Processing Technology, v. 148, p. 163-174, 2016.

MIRANDA, M. T.; ARRANZ, J.I.; ROJAS, S.; MONTERO, I. 
Energetic characterization of densified residues from Pyrenean oak forest. Fuel, v. 88, n. 11, p. 2106-2112, 2009.

NADIAH, F.; ABD, B. Production and characterization of bamboo fibre reinforced. Bioscience Journal, v. 2012, p. 922930, 2016.

PEREIRA, B. L. C.; CARNEIRO, A.C.O.; CARVALHO, A.M.M.L.; VITAL, B.R.; OLIVEIRA, A.C.; CANAL, W.D. Influência da adição de lignina kraft nas propriedades de pellets de eucalipto. Floresta, v. 46, n. 2, p. 235-242, 2016.

PINTO, A. A. S.; PEREIRA, B.L.C.; CÂNDIDO, W.L.; OLIVEIRA, A.C.; CARNEIRO, C.O.; CARVALHO, A.M.M.L. Caracterização de pellets de ponteira de eucalipto. Revista Ciência da Madeira, v. 6, n. 3, p. 232-236, 2015.

PROTÁSIO, T.P.; BUFALINO, L.; MENDES, R.F.; RIBEIRO, M.X.; TRUGILHO, P.F.; LEITE, E.R. Torrefação e carbonização de briquetes de resíduos do processamento dos grãos de café. Revista Brasileira de Engenharia Agrícola e Ambiental, v. 16, n. 11, p. 1252-1258, 2012.

PROTÁSIO, T.P.; TRUGILHO, P. F.; SIQUEIRA, H.F.; MELLO, I.C.N.A.; ANDRA, C.R.; GUIMARÃES JÚNIOR, J.B. Caracterização energética de pellets in natura e torrificados produzidos com madeira residual de Pinus. Pesquisa Florestal Brasileira, v. 35, n. 84, p. 435-442, 2015.

PROTÁSIO, T. P.; BUfAlinO, L.; TONOLI, G. H. D.; COUTO, A. M.; TRUGILHO, P. F.; GUIMARÃES JÚNIOR, M. Relação entre o poder calorífico superior e os componentes elementares e minerais da biomassa vegetal. Pesquisa Florestal Brasileira, v. 31, n. 66, p. 113-122, 2011.

PROTÁSIO, T. P.; BUFALINO, L. GUIMARÃES JUNIOR, M.; TONOLI, G. H.D.; TRUGILHO, P. F. Técnicas multivariadas aplicadas à avaliação de resíduos lignocelulósicos para a produção de bioenergia. Ciência Florestal, v. 23, n. 4, p. 771-781, 2013a.

PROTÁSIO, T. P.; BUfALINO, L.; TONOLI, G. H. D.; GUIMARÃES JUNIOR, M.; TRUGILHO, P. F.; MENDES, L. M. Brazilian lignocellulosic wastes for bioenergy production: characterization and comparison with fossil fuels. Bioresources, v. 8, p. 1166-1185, 2013b.

SPANHOL, A.; NONES, D. L.; KUMABE, F. J. B.; BRAND, M. A. Qualidade dos pellets de biomassa florestal produzidos em santa catarina para a geração de energia. Floresta, v. 45, n. 4 , p. 833-843, 2015.
TIMUNG, R.; MOHAN, M.; CHILUKOTI, B.; SASMAL, S.; BANERJEE, T.; GOUD, V.V. Optimization of dilute acid and hot water pretreatment of different lignocellulosic biomass: A comparative study. Biomass and Bioenergy, v. 81, p. 9-18, 2015 .

TOSCANO, G.; DUCA, D.; AMATO, A.; PIZZI, A. Emission from realistic utilization of wood pellet stove. Energy, v. 68, n.15, p. 644-650, 2014.

TUMULURU, J. S. Effect of process variables on the density and durability of the pellets made from high moisture corn stover. Biosystems Engineering, v. 119, p. 44-57, 2014.

VASSILEV, S. V.; BAXTER, D.; ANDERSEN, L.K.; VASSILEVA, C. G. An overview of the chemical composition of biomass. Fuel, v. 89, n. 5, p. 913-933, 2010.

VASSILEV, S. V.; BAXTER, D.; ANDERSEN, L.K.; VASSILEVA, C. G. An overview of the composition and application of biomass ash.Part 2. Potential utilisation, technological and ecological advantages and challenges. Fuel, v. 105, n. 5, p. 19-39, mar. 2013.

VASSILEV, S. V.; BAXTER, D.; VASSILEVA, C. G. An overview of the behaviour of biomass during combustion: Part II. Ash fusion and ash formation mechanisms of biomass types. Fuel, v. 117, p. 152-183, 2014. 